\title{
KEEFEKTIFAN MULTIMEDIA PEMBELAJARAN BERBASIS COURSELAB PADA PRINSIP KERJA ENGINE BIDANG KEAHLIAN KENDARAAN RINGAN
}

\author{
Imam Wahyudi ${ }^{1, \unrhd}$, Abdul Azis Abdillah ${ }^{2}$ \\ Program Studi Alat Berat, Jurusan Teknik Mesin, Politeknik Negeri Jakarta.

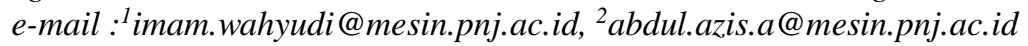

\begin{abstract}
This research is a development research that is focused on developing CourseLab-based Learning Devices on the Principle of Work Engine for 11th grade students, SMK Darussalam Makassar. The research model used in this study refers to the model developed by Dick \& Carey which consists of three stages, namely (1) Identification Phase, At this stage the researcher clarifies the objectives, conducts instructional analysis of learning, and identifies initial behavior and characteristics of students; (2) Development Phase, at this stage the researcher develops courselab-based learning media with the activities of formulating objectives and benchmark reference tests, and developing learning strategies and tools, (3) testing and evaluation stages. Furthermore, the CourseLab-based learning tool that has been developed is then validated by two experts to determine whether the learning device is valid and is suitable for use. The results showed that, the learning tools that had been developed were declared valid by experts. Thus, learning tools are appropriate for self-study.
\end{abstract}

Keywords : CourseLab, Engine, Development Research

\begin{abstract}
ABSTRAK
Penelitian ini bertujuan untuk mengembangkan Perangkat Pembelajaran berbasis CourseLab pada Prinsip Kerja Engine untuk siswa kelas 11, SMK Darussalam Makassar. Jenis penelitian yang digunakan adalah $R \&$ \& dengan mengacu pada model yang dikembangkan oleh Dick \& Carey. Model ini terdiri dari tiga tahap, yaitu (1) tahap identifikasi; (2) tahap pengembangan; (3) tahap ujicoba dan evaluasi. Pada tahap identifikasi peneliti mengklarifikasi tujuan, melakukan analisis instruksional pembelajaran, serta mengidentifikasi tingkah laku awal dan karakteristik siswa, selanjutnya pada tahap pengembangan peneliti mengembangkan media pembelajaran berbasis courselab dengan mempersiapkan perangkat pembelajaran. Tahapan terakhir, perangkat pembelajaran berbasis CourseLab yang telah dikembangkan tersebut divalidasi oleh dua orang ahli untuk menentukan apakah perangkat pembelajaran tersebut valid dan layak untuk digunakan. Hasil validasi menunjukkan bahwa, perangkat pembelajaran yang telah dikembangkan dinyatakan valid oleh para ahli. Sehingga, perangkat pembelajaran layak digunakan untuk belajar mandiri.
\end{abstract}

Kata kunci : CourseLab, Engine, Development Research

\section{PENDAHULUAN}

Upaya untuk meningkatkan mutu pendidikan di Indonesia, khususnya pendidikan vokasi dengan kompetensi keahlian kendaraan ringan masih terus diupayakan. Akan tetapi hasil evaluasi di akhir tahun pelajaran masih menunjukkan bahwa pelajaran Sistem Engine tidak pernah menempati rating sebagai pelajaran dengan nilai rata-rata tertinggi yang dimiliki oleh siswa. Seperti yang tergambar pada Tabel 1 berikut.
Tabel di atas merupakan data perolehan nilai pada sistem Engine di kelas XI SMK Darussalam Makassar dari tahun 2009 - 2011. Dari tabel tersebut terlihat bahwa rata-rata hasil belajar sistem engine siswa selama 3 tahun berturutturut belum mencapai kriteria ketuntasan minimal (KKM) yang ditetapkan oleh SMK Darussalam Makassar yaitu 70.00.

Setelah dilakukan observasi diketahui bahwa ada beberapa faktor yang mempengaruhi rendahnya hasil belajar sistem engine siswa SMK Darussalam Makassar tersebut antara lain, (1) sarana dan prasarana di laboratorium masih 
kurang, (2) ketersediaan sumber belajar kurang, dan motivasi mencari informasi melalui berbagai sumber majalah buku internet sangat rendah. Selain itu berdasarkan wawancara peneliti dengan beberapa orang guru, diperoleh informasi bahwa masih banyak guru termasuk guru kelas IX di SMK Darussalam Makassar yang belum membuat atau menggunakan perangkat pembelajaran dan dalam kegiatan belajar mengajarnya pun guru masih menggunakan metode ceramah.

Berdasarkan kondisi di atas, perlu dilakukan suatu tindakan agar nilai siswa lebih ditingkatkan. Sebagai salah satu faktor penting dalam keberhasilan belajar bukan berarti pembelajaran harus berpusat pada guru dimana semua materi diberikan oleh guru sedangkan siswa hanya duduk manis dan mendengarkan guru menjelaskan materi. Akan dalam proses pembelajaran guru lebih bertindak sebagai fasilitator dan motivator. Sebagai fasilitator artinya guru senantiasa memberikan fasilitas dan kemudahan dalam proses pembelajaran, sedangkan sebagai motivator berarti guru meningkatkan kegairahan dan pengembangan kegiatan belajar peserta didik. Guru harus mampu memberikan dorongan untuk mendinamiskan potensi, aktivitas, dan kreativitas sehingga akan terjadi dinamika di dalam proses pembelajaran [1][2][3].

Salah satu upaya agar terciptanya pembelajaran yang aktif, kreatif, bermakna dan membuat kegiatan belajar mengajar menjadi dua arah yaitu dengan mengembangkan perangkat pembelajaran. Salah satu perangkat pembelajaran yang dapat dikembangkan adalah media pembelajaran. Latuheru [4][5][6] mengumpulkan beberapa pendapat tentang manfaat media pembelajaran, diantaranya Rowntree yang menyatakan bahwa media pembelajaran membangkitkan motovasi belajar para siswa atau anak didik, dapat merangsang anak didik untuk belajar dengan penuh semangat. Berdasarkan pendapat tersebut dapat disimpulkan bahwa media merupakan salah satu faktor penting dalam keberhasilan siswa dalam membuat siswa semangat untuk belajar.

Dalam penelitian ini media pembelajaran yang digunakan adalah Courselab. CourseLab merupakan aplikasi yang berfungsi sebagai penyusun multimedia (multimedia authoring). Aplikasi ini mampu menangani penyusunan berbagai media seperti teks, gambar, animasi Flash, video, serta memiliki fitur bahasa pemrograman interaktif (seperti bahasa Action Script di Flash). Websoft CourseLab merupakan sistem authoring e-learning yang mudah digunakan dan unggul untuk membuat konten elearning interaktif berkualitas tinggi [7][8][9].

Digunakannya courselab sebagai salah satu perangkat pembelajaran diharapkan tidak hanya sebagai media pembelajaran namun juga sebagai bahan ajar interaktif yang nantinya bisa digunakan ataupun diakses peserta didik dapat dari mana saja dan dipelajari kapan saja.

Di sisi lain, dengan bahan ajar model seperti ini diharapkan aktifitas pembelajaran dan kualitas keilmuan dapat semakin meningkat guru dapat melakukan pengembangan bahan ajar multimedia secara mandiri. Hal tersebut juga sejalan dengan pergeseran sistem pendidikan kearah sistem modern dengan karakteristik yang digambarkan, pada akhirnya akan mengubah lembaga lembaga pendidikan di Indonesia menjadi institusi pembelajaran yang kreatif, interaktif, dan dinamis. Institusi pembelajaran sistem modern akan memberi motivasi kepada siswa untuk memiliki sifat selalu ingin tahu, kreatif, anti kemonotonan, dan berjiwa dinamis. Oleh karena itu, penelitian ini sangat penting dilakukan dalam upaya meningkatkan kualitas pembelajaran, guru perlu mengembangkan perangkat pembelajaran berbasis Courselab yang 
valid, efektif dan praktis sehingga dapat membantu peserta didik untuk aktif membangun pemahaman sendiri, memberikan kemudahan, dan dapat membantu guru dalam melaksanakan kegiatan pembelajaran. Penelitian ini bertujuan untuk mengembangkan perangkat pembelajaran berbasis courselab pada prinsip kerja engine bidang keahlian kendaraan ringan SMK Darussalam Makassar.

\section{Courselab}

Dalam proses belajar mengajar, fungsi media menurut Sudjana [10] yakni: 1) penggunaan media dalam proses belajar mengajar, bukan merupakan fungsi tambahan, tetapi mempunyai fungsi sendiri sebagai alat bantu untuk mewujudkan situasi belajar dan mengajar yang efektif; 2) penggunaan media pembelajaran merupakan bagian yang integral dari keseluruhan situasi mengajar. Ini berarti bahwa media pengajaran merupakan salah satu unsur yang harus dikembangkan oleh seorang pendidik; 3) penggunaan media pembelajaran lebih diutamakan untuk mempercepat proses belajar mengajar dan membantu peserta didik dalam menangkap materi yang diberikan oleh pendidik. Hasil penelitian Peter Shea mengungkapkan siswa dapat menyerap suatu materi sebanyak 90\% dari apa yang dikatakan dan dilakukan, 70\% dari apa yang dikatakan, 50\% dari apa yang didengar dan dilihat (audio visual), sedangkan dari yang dilihatnya hanya $30 \%$, dari yang didengarnya hanya $20 \%$, dan dari yang dibaca hanya 10\%. Dengan demikian, penggunaan media komputer dapat menjadi perangkat ampuh untuk pengajaran dan pendidikan [11]. Winkel [12] mengemukakan bahwa penggunaan komputer dalam pembelajaran di dalam kelas dapat berperan sebagai guru/dosen, karena materi pelajaran telah diprogramkan dan terdapat dalam ingatan komputer (memory). Sejumlah siswa dapat mempelajari materi yang sama pada waktu yang sama, masing-masing siswa menangani suatu terminal yang dihubungkan dengan komputer pusat. Sunaryo Soenarto [13] menjelaskan pula bahwa komputer digunakan dalam pembelajaran dapat memberikan manfaat: (1) penggunaan perangkat lunak jauh lebih baik untuk menyajikan bahan ajar yang mempunyai struktur baku seperti matematika, (2) peran komputer bergeser dari media yang digunakan untuk menyajikan bahan ajar menjadi media yang mampu memainkan sebagai sumber belajar siswa, 3) peran komputer telah menggeser konsep belajar di ruang kelas menuju konsep belajar di ruang cyber dalam konteks lingkungan yang lebih luas.

CourseLab merupakan sistem authoring e-learning yang mudah digunakan dan unggul untuk membuat konten ELearning interaktif berkualitas tinggi. CourseLab merupakan piranti lunak penyusun bahan ajar multimedia untuk e-Learning yang tangguh dan mudah digunakan. Konten e-learning dapat disebarkan melalui internet, Learning Management Systems (LMS), CD-ROM dan piranti lainnya. Ditinjau dari perspekstif metodologi pendidikan, CourseLab sesuai dengan prinsip pembelajaran modern dan Pembelajaran mengandung materi ajar dan penilaian.Pada dasarnya terdapat 4 (empat) langkah besar pengembangan bahan ajar multimediamenggunakan Courselab, yaitu : membuat project baru, mengisi halaman depan, membuat slide bahan ajar dan melakukan publikasi.

CourseLab [7]-[9] menawarkan lingkungan What You See Is What You Get (WYSIWYG) yang bebas dari pemrograman untuk menghasilkan bahan ajar interaktif berkualitas tinggi yang dapat dipublikasikan di Internet, Learning Management Systems (LMS), serta CD-ROM.Dengan memaanfaatkan courslab, maka akan menghasilkan proses belajar mengajar yang aktif dan 
maksimal.Hal yang menjadi fokus pembelajaran menggunakan Courselab adalah bagaimana penyajian dan pengelolaan materi pelajaran dapat menarik peserta didik agar mampu menstimulasi motivasi dan potensinya dengan mantap [14]. Dalam usaha mengaplikasikan pembelajaran multimedia berbasis courselab bukanlah hal yang mudah, karena harus disesuaikan dengan karakteristik tiaptiap materi pembelajaran. Penelitian ini mencoba mendesign aplikasi courselab yang sesuai peruntukannya untuk siswa Jurusan Otomotif SMK Darussalam Makassar.

\section{METODE PENELITIAN}

Penelitian ini adalah penelitian pengembangan (Research and Development) Dalam pengembangan perangkat pembelajaran dikenal tiga macam model pengembangan perangkat, yaitu: model Dick-Carey [15], model 4D dan model Kemp [10]. lanjut Dick \& Carey [15], urutan langkah yang harus dilaksanakan adalah (1) mengidentifikasi tujuan instruksional; (2) melakukan analisis instruksional; (3) Identifikasi kemampuan awal dan karakteristik pembelajar; (4) Menuliskan tujuan instruksional khusus; (5) Mengembangkan item test criterionreferenced;

Mengembangkan strateri pembelajaran; (7) Mengembangkan dan memilih material instruksional; (8) Mendisain dan melakukan evaluasi formatif; (9) Merevisi kembali pembelajaran; dan (10) Mendisain dan melakukan evaluasi sumatif. Pada model di atas, evaluasi formatif (langkah 8) atau evaluasi yang dilakukan saat proses, dilaksanakan sepanjang proses pengembangan, dan hasilnya digunakan untuk meninjau kembali pembelajaran (langkah 9). Evaluasi sumatif, atau evaluasi untuk menentukan efektivitas dari produk, dilakukan pada langkah ke 10. Penelitian ini adalah penelitian dan pengembangan yang menciptakan program pembelajaran yang efektif, efisien, dan menarik. Hal senada juga dinyatakan oleh [15] bahwa penelitian pengembangan bukan untuk membuat teori atau menguji teori melainkan untuk mengembangkan produk-produk yang efektif untuk digunakan di sekolah.

Penelitian ini, model yang menjadi acuan adalah model penelitian Pengembangan Dick \& Carey melalui 3 tahap berikut.Pertama adalah tahap identifikasi, Tahap ini bertujuan untuk mengumpulkan informasi yang relevan dengan perlunya pengembangan pembelajaran multimedia berbasis courselab. Kedua adalah tahap pengembangan. Tahap ini bertujuan untuk mengembangkan desain pembelajaran hingga menghasilkan suatu perangkat pembelajaran berbasis courselab, ketiga adalah tahap uji coba dan evaluasi, tahap ini bertujuan untuk mengetahui bagaimana hasil evaluasi perangkat pembelajaran pembelajaran berbasis courselab. Diagram alir penelitian dapat dilihat pada gambar 1 .

Pada penelitian ini, tahap uji coba yang dilakukan adalah validasi ahli. Uji coba ini dimaksudkan untuk mengumpulkan data tentang kualitas perangkat. Untuk memperoleh informasi tentang kriteria kevalidan, kepraktisan dan keefektifan media yang dihasilkan, maka perlu dikembangkan instrumen. Menurut Upu [16] uji coba ini merupakan rangkaian dari kegiatan tes, evaluasi dan revisi perangkat yang dikembangkan dengan tujuan untuk menguji perangkat pembelajaran berbasis courseLab yang dikembangkan memenuhi kriteria valid. Kevalidan berarti bersifat valid sedangkan validitas adalah suatu ukuran yang menunjukkan tingkat kevalidan atau kesahihan suatu instrumen. Pengertian validitas senantiasa dikaitkan dengan penelitian empiris dan pembuktian-pembuktiannya bergantung 
pada macam validitas yang digunakan [17]. Validasi ahli, dilakukan oleh pakar untuk mengevaluasi, mengoreksi, dan mengarahkan rancangan perangkat pembelajaran yang telah dirancang. Validasi ahli yang terlibat dalam hal ini terdiri dari pakar dalam bidang teknik pengembangan materi sistem engine dan pakar dalam bidang perangkat pembelajaran setelah divalidasi melakukan revisi terhadap perangkat pembelajaran berbasis Courselab dan seluruh instrumen berdasarkan saran dari validator.

\section{Waktu dan Tempat}

Penelitian ini dilaksanakan di SMK Darussalam Makassar dan subjek penelitiannya adalah siswa kelas XI OTO Bidang Keahlian Teknik Kendaraan ringan pada semester Ganjil tahun pelajaran 2012/2013.

\section{HASIL DAN PEMBAHASAN}

Validasi perangkat pembelajaran berbasis courselab dilakukan oleh 2 (dua) orang ahli. Kegiatan Validasi dilakukan dengan memberikan naskah perangkat pembelajaran berbasis courselab beserta lembar validasinya kepada para validator.Penilaian dimaksudkan untuk melihat validitas pembelajaran, isi, dan bahasa yang mencakup semua perangkat yang dikembangkan. Hasil validasi para ahli digunakan sebagai dasar untuk melakukan revisi dan penyempurnaan terhadap perangkat pembelajaran. Perangkat pembelajaran hasil revisi berdasarkan masukan dari para validator ini selanjutnya akan diuji cobakan.

Secara umum,hasil penilaian ahli terhadap perangkat dapat dilihat pada Tabel 3. Berdasarkan hasil analisis validitas perangkat pembelajaran maka dapat disimpulkan bahwa perangkat pembelajaran berbasis courselab yang terdiri dari Buku Siswa (BS), Lembar Kegiatan Siswa (LKS), Rencana
Pelaksanaan Pembelajaran (RPP), dan Tes Hasil Belajar (THB) menurut penilaian ahli telah memenuhi kriteria kevalidan dengan kategori valid. Hal ini menunjukkan bahwa perangkat pembelajaran tersebut telah layak untuk diuji cobakan.

\section{KESIMPULAN}

Perangkat

pembelajaranberbasis CourseLab telah dikembangkan mengacu pada model Dick \& Carey, yang meliputi: (1) tahap identifikasi, (2) tahap pengembangan. (3) tahap uji coba dan evaluasi. Tahapan pengembangan berbasis CourseLab ditekankan dalam proses pembelajaran pada kegiatan inti dengan topik Prinsip Kerja Engine dengan menggunakan media CourseLab. Semua desain yang dikembangkan divalidasi oleh ahli. Berdasarkan hasil penelitian yang telah dilakukan, semua perangkat pembelajaran yang telah dikembangkan telah memenuhi kriteria valid. Sehingga perangkat pembelajaran layak digunakan untuk belajar mandiri.

\section{DAFTAR PUSTAKA}

[1] W. Sanjaya, Strategi Pembelajaran Berorientasi Standar Proses Pendidikan. Jakarta: Kencana Prenada Media, 2007.

[2] H. Sahidu, G. Gunawan, R. Joni, and R. Satutik, "Pengembangan Perangkat Pembelajaran Fisika Berorientasi Pada Kreativitas Calon Guru.," J. Pendidik. Fis. dan Teknol., vol. 4, no. 1, 2018.

[3] D. J. Priansa, Pengembangan Strategi Dan Model Pembelajaran: Inovatif, Kreatif, dan prestatif dalam memahami peserta didik. 2017.

[4] KaroKaro, I. Rasyid, and R. Rohani, "Manfaat media dalam pembelajaran,” AXIOM J. Pendidik. Dan Mat., vol. 7, no. 1, 2018. 
[5] J. D. Latuheru, Media Pembelajaran: Dalam Proses Belajar Masa Kini. Makasar: Universitas Negeri Makasar, 2002.

[6] R. Rohani, Media pembelajaran. 2019.

[7] A. D. Putra, M. Murtiani, and G. Gusnedi, "PEMBUATAN MODUL INTERAKTIF TERINTEGRASI GUIDED INQUIRY MENGGUNAKAN APLIKASI COURSE LAB UNTUK MATERI USAHA, ENERGI, MOMENTUM DAN IMPULS PADA PEMBELAJARAN FISIKA SMA KELAS X," PILLAR Phys. Educ., vol. 10, no. 1, 2017.

[8] T. Y. Setyawan, "Primary school pre-service teachers' technology self-efficacy in creating e-learning content using CourseLab 2.4," $J$. Inov. Teknol. Pendidik., vol. 6, no. 2, 2019.

[9] A. Novandi, B. Asto, and I. G. Putu, "Pengembangan media pembelajaran presentasi menggunakan courselab 2.4 pada kompetensi dasar-dasar elektronika digital di smk 3 negeri surabaya," $J$. Pendidik. Tek. Elektro, vol. 5, no. 1, 2016.

[10] N. Sudjana, Dasar-Dasar Proses Belajar Mengajar. Bandung: Sinar Baru Aglensindo, 1988.

[11]R. Isnanto, “Aplikasi Teknologi Multimedia pada Bidang Pendidikan Sains dan Teknologi,” 2004.
[12]W. S. Winkel, Psikologi Pengajaran. Jakarta: Grasindo, 1996.

[13] S. Soenarto, "Pengembangan multimedia pembelajaran Interaktif mata kuliah tata bidang Inotek," $J$. /inovasi dan Apl. Teknol., vol. 9, no. 1, 2005.

[14]A. H. Sutopo, Multimedia interaktif dengan flash. Yogyakarta: Graha Ilmu, 2012.

[15] W. Dick, L. Carey, and J. O. Carey, The systematic design of instruction. Boston: Harper Collin College Publisher, 2005.

[16] H. Upu, "Developing Mathematics Instructional Packages Using Stad Type Of Cooperative Model Of Grade Viii-2 Junior High School 30,” 2010. http://blog.unm.ac.id/hamzahupu/20 10/09/21/developing- mathematicsinstructional-packages-using-stadtype-of-cooperative-model-ofgrade-viii-2-junior-high-school-30makassar/.

[17]Ekawati. E., "Pengembangan Instrumen Penilaian Pembelajaran Matematika SD/SMP,” Yogyakarta, 2011. 
Tabel 1: Nilai Sistem Engine Teknik Kendaraan Ringan SMK Darussalam

\begin{tabular}{llll}
\hline No. & Tahun & Nilai & KKM \\
\hline $\mathbf{1}$ & 2009 & 65 & 70.00 \\
$\mathbf{2}$ & 2010 & 68.7 & 70.00 \\
$\mathbf{3}$ & 2011 & 67.5 & 70.00 \\
\hline \multicolumn{2}{l}{ Sumber : Guru Mata pelajaran Sistem Engine SMK Darussalam Makassar }
\end{tabular}

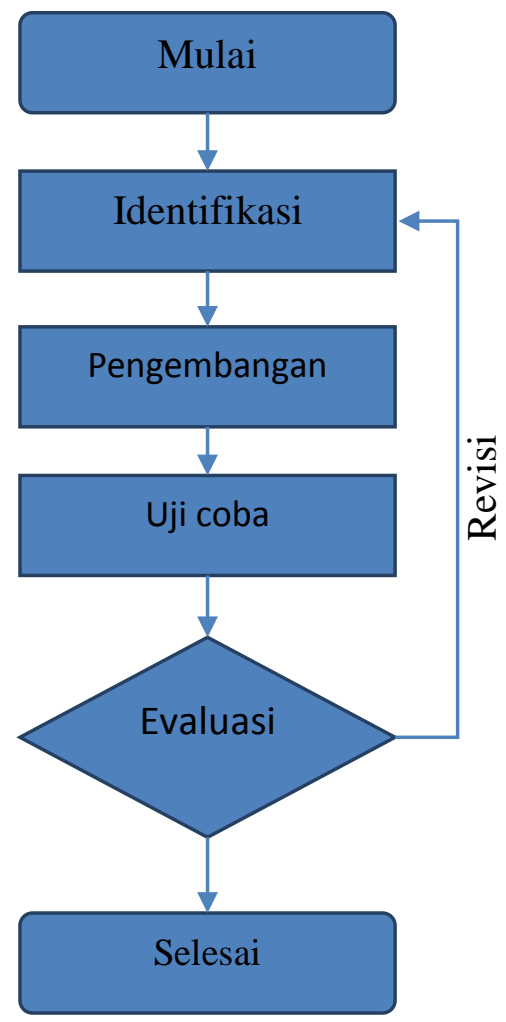

Gambar 1. Diagram alir penelitian

Tabel 2 Hasil Revisi Perangkat Pembelajaran

\begin{tabular}{|c|c|c|}
\hline $\begin{array}{c}\text { Aspek Yang } \\
\text { direvisi }\end{array}$ & Sebelum revisi & Sesudah Revisi \\
\hline Buku Siswa & $\begin{array}{l}\text { - Penulisan kata yang berbahasa } \\
\text { inggris harus dimiringkan } \\
\text { seperti:complete building up } \\
\text { - Nama gambar tidak dicantumkan } \\
\text { - Penulisan antara kata tidak berspasi } \\
\text { - Pengaturan tata letak tidak } \\
\text { tertata }\end{array}$ & $\begin{array}{l}\text { - Penulisan sudah } \\
\text { dimiringkan, seperti } \\
\text { complete building up } \\
\text { - Nama gambar sudah } \\
\text { tercantum } \\
\text { - Letak antara kata sudah } \\
\text { berspasi } \\
\text { - Pengaturan tata letak } \\
\text { sudah tertata }\end{array}$ \\
\hline $\begin{array}{c}\text { Lembar } \\
\text { kegiatan Siswa }\end{array}$ & $\begin{array}{l}\text { - } \text { Penulisan antara kata tidak berspasi } \\
\text { - Pengaturan tata letak tidak } \\
\text { tertata }\end{array}$ & $\begin{array}{l}\text { - Letak antara kata sudah } \\
\text { berspasi } \\
\text { - Pengaturan tata } \\
\text { letak sudah tertata }\end{array}$ \\
\hline $\begin{array}{l}\text { Rancangan } \\
\text { Program } \\
\text { pembelajaran }\end{array}$ & $\begin{array}{l}\text { - } \quad \text { Belum ada skor pada kunci } \\
\text { jawaban. } \\
\text { - Setiap kegiatan guru harus diikuti }\end{array}$ & $\begin{array}{l}\text { - Dibuat skor pada kunci } \\
\text { jawaban. } \\
\text { - Kegiatan siswa: }\end{array}$ \\
\hline
\end{tabular}




\begin{tabular}{|c|c|c|}
\hline & 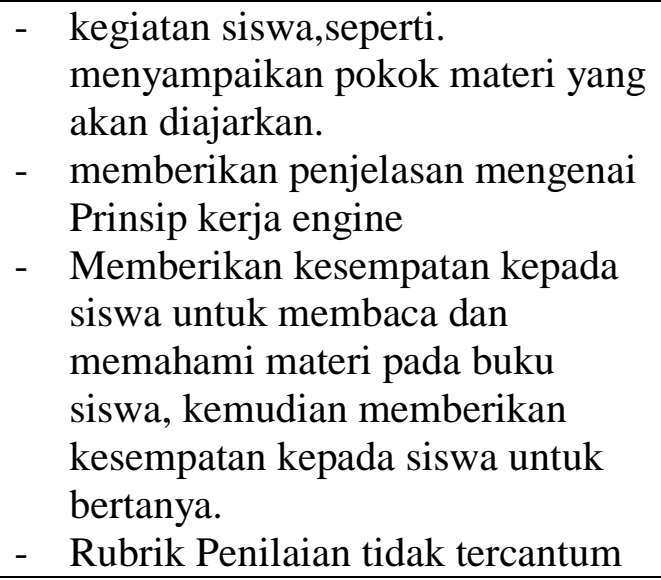 & $\begin{array}{l}\text { - menyimak apa yang } \\
\text { disampaikan oleh guru. } \\
\text { - Mendengarkan dan } \\
\text { memperhatikan } \\
\text { penjelasan guru. } \\
\text { - Mempelajari materi } \\
\text { pada buku siswa } \\
\text { dengan bertanya jika } \\
\text { ada yang belum } \\
\text { dipahami. } \\
\text { - Rubrik penilaian sudah } \\
\text { tercantum }\end{array}$ \\
\hline $\begin{array}{l}\text { Tes hasil } \\
\text { Belajar }\end{array}$ & $\begin{array}{l}\text { - Kesesuaian soal dengan materi } \\
\text { pembelajaran }\end{array}$ & $\begin{array}{l}\text { - penyesuaian soal dan } \\
\text { materi }\end{array}$ \\
\hline
\end{tabular}

Tabel 3 Rekapitulasi Hasil Validasi

\begin{tabular}{lll}
\hline Sumber & Skor rata-rata penilaian & Ket \\
\hline RPP & 3,5 & Valid \\
Buku Siswa & 3,3 & Valid \\
LKS & 3,4 & Valid \\
THB & 3,1 & Valid \\
\hline
\end{tabular}

